\title{
MECHANISING OIL PALM LOOSE FRUITS COLLECTION - A REVIEW
}

\author{
MOHD RAMDHAN KHALID*; ABD RAHIM SHUIB* and NORMAN KAMARUDIN*
}

\begin{abstract}
The presence of oil palm loose fruits (LF) on the ground is one of the indicators that the fresh fruit bunch $(F F B)$ is ready to be harvested. LF are also present when the bunch falls to the ground during the cutting operation, and these fruits need to be collected together to maximise the oil content during processing. Even after a century since this crop was first planted commercially in Malaysia, no major changes have been made in terms of how LF are being collected in the plantation. The collection is done manually by hand picking or by using a raking device and the LF are eventually placed into a bag or directly into a container or trailer. This activity involves frequent bending movement which causes backache to the worker. To minimise this problem and to increase the collection productivity, various tools and machines, from using a simple mechanical picking mechanism to vacuum-type collecting machines were developed. Recently, the focus was concentrated towards the unmanned collection concept. This article reviews most of the developing technologies related to mechanised oil palm LF collection and their technical limitations. Design, working system and cost considerations for the future development of LF collecting machine are also described.
\end{abstract}

Keywords: oil palm, loose fruits, manual collection, mechanised collection, cost consideration.

Received: 3 December 2019; Accepted: 1July 2020; Published online: 22 September 2020.

\section{INTRODUCTION}

Oil palm planted area in Malaysia has reached 5.85 million hectares since it was first planted as a commercial crop in 1917 (Kushairi et al., 2019). The RM 67.74 billion industry is still relying extensively on foreign labour especially in the plantation sector. Mechanising field operation seems to be the best approach to minimise foreign labour dependency by providing greater output per hectare. However, the acceptance and the implementation of mechanisation in the industry can still be considered very low. Azman et al. (2017) rated the level of mechanisation in the oil palm plantation at $1.9 \%$ for the harvesting and $16.2 \%$ for the in-field collection operations. Workers remain

\footnotetext{
Malaysian Palm Oil Board, 6 Persiaran Institusi, Bandar Baru Bangi, 43000 Kajang, Selangor, Malaysia.

E-mail: ramdhan@mpob.gov.my
}

using either the manual or semi-mechanised tools. To overcome these issues, improvement on the human-machine connection is required during product design and product manufacturers need to play a role to disseminate information and to provide training to the workers (Nur Syazwani et al., 2015).

Two areas needing major changes in terms of technology adoption are harvesting and loose fruits (LF) collection. The introduction of a motorised cutter (Cantas) can be considered as a breakthrough in mechanising harvesting operation (Abdul Razak et al., 2008). However, it is limited by height (less than $5 \mathrm{~m}$ palm height). Numerous on-going studies are being conducted by the Malaysian Palm Oil Board (MPOB) to increase the reachable height and its performance. Nevertheless, for LF collection, the industry is still counting on manual method although several technologies were introduced by research institutes and universities, together with trials conducted by the industry itself. 


\section{LOOSE FRUITS}

LF generally have the highest oil content than most of the attached fruits in the bunch. The presence of LF in the field are from two sources: first, those naturally detached when the fresh fruit bunch (FFB) is ripe and ready to be harvested, and second, those that are scattered on the ground during the harvesting activity. It is a common practice that when there are 1-10 LF on the ground, the cutting activity can be performed immediately as the bunch is already ripe. A study by Azali et al. (2015) revealed that during harvesting, the majority of LF are scattered in a radius of 1.5-2.5 m from the FFB impact point.

Depending on their variety and palm age, the weight of the FFB ranges between 10-40 kg and the fruitlet ranges from 6-20 g (Razali et al., 2012). The average length, width and thickness of fruitlets vary from $30-35 \mathrm{~mm}, 20-27 \mathrm{~mm}$ and $17-24 \mathrm{~mm}$, respectively (Owolarafe et al., 2006; Mohd Hafiz and Abdul Rashid, 2011; Renel et al., 2013). They also stated that oil palm fruit has about $70 \%-80 \%$ of sphericity which indicates that the fruitlet has a spherical shape.

Years ago, LF were neglected by plantations, being left in the field due to the perception of their small size, hence, not worth to be collected. Nowadays, thanks to intensive research works, uncollected LF is considered as losses to the oil palm industry due to its maximum level of oil content. The majority of the detached LF are from the outer diameter of the bunch. The fruits are huge and contain the highest oil. Studies showed that fruits from the outer diameter of a bunch contribute up to $40 \%$ of palm oil compared to the middle and inner regions of spikelet, i.e. 35\% and 29\% (Henson, 2012). Hence, there will be a significant reduction in oil extraction rate (OER) if LF are not collected and processed. A study by Gan et al. (1993) indicated that if $20 \mathrm{LF}$ per bunch are not collected, there will be a reduction on OER by $0.92 \%, 0.46 \%$ and $0.37 \%$ for palm aged 1-5 years, 6-15 years and above 15 years (years after the first harvesting), respectively.

Many plantations are now realising this fact and efforts are geared towards ensuring that all LF are collected from the field to maximise their profits. Sime Darby Plantation Sdn Bhd reported that the company would make an additional RM 30 million in net profit if estate workers collect six LF per palm (Seedlink, 2008). Unfortunately, studies by Afroza et al. (2015) and Nurul Fadilah et al. (2019) revealed that there are still between 10\%-30\% of LF which are not being collected by the independent smallholders. The uncollected LF will eventually grow and turn into weeds or volunteer oil palm seedlings (VOPS) (Maizatul-Suriza and Idris, 2012). There are also possibilities that the VOPS will be taken by irresponsible individuals, to be sold as planting materials. It is, therefore, vital that LF are fully collected. The typical LF collection system can be summarised as in Figure 1.

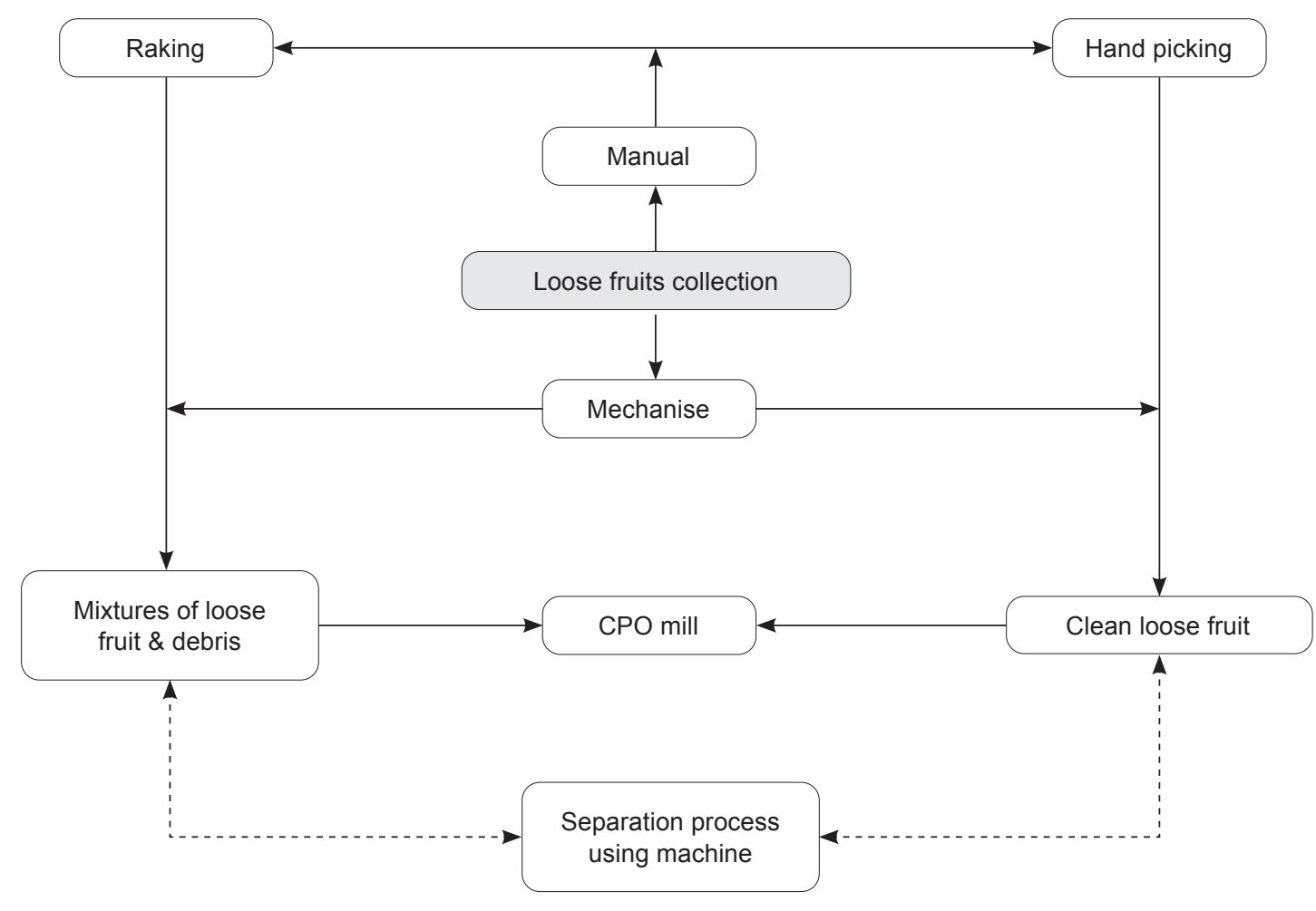

Figure 1. Flow chart of loose fruit collection system. 


\section{Manual Collection of Loose Fruit}

LF must be collected and gathered with other bunches. Currently, conventional methods are being widely practised in plantations with the productivity ranging from $200-250 \mathrm{~kg}$ per worker per day (Abd Rahim et al., 2018). LF are normally picked up by hand and collected in a bucket or bag. Besides that, there are also different options like using rakes, planks and scoops (Figure 2). It is estimated that the time taken to collect LF is about $30 \%-60 \%$ of the total FFB handling time (Mohd Zohadie, 1992; Henson, 2012; Nizaroyani Saibani et al., 2015).

Depending on the estate's standard practice, the collection of LF is done either by the harvesters themselves or by a separate group of female workers (Martin et al., 2016). To accomplish the job, the worker has to frequently bend down to collect the scattered LF and move from palm to palm. Although this activity is performed within a short period, it is however being repeated daily, which indirectly promotes an incorrect body posture $(\mathrm{Ng}$ et al., 2013; Ezrin et al., 2016). The worker is prone to fatigue and back pain which may lead to poor productivity (Nur Syazwani et al., 2016).

The presence of debris that accumulate together with LF during collection is one of major problems. A study by Darius and Fairulnizam (2014) revealed that a manual method of using sack or wheelbarrow, about 27\%-38\% debris was accumulated within the collected LF. These trashes are potential to contribute for lower OER as the trash will absorb oil during processing. Hence, there is a need to remove the debris before the LF are sent for processing. Several potential cleaning or segregating machines are available for the industry (Ahmad Zamri and Mohd Zulfahmi, 2017; Gemka, 2017; Mohd Ramdhan and Abd Rahim, 2017).

\section{Mechanised Methods}

A practical and cost-effective mechanised LF collection system is still one of the primary targets of the oil palm industry. There is a need to increase the efficiency of the LF collection but at the same time, the cost is kept at a minimum. Efforts to lighten and improve the method of collecting LF were initiated in the late 1980 s as conducted by Muhammad Salih and Razak (1988). Abd Rahim et al. (2011) reported that several designs to collect LF have been invented, but most have never been commercialised due to the various technical limitations and constraints.

Two approaches were tested to assist LF collection activity, i.e. mechanical and suction systems. Both of these approaches have their advantages and disadvantages, which will be discussed.
Mechanical type. Among the earliest works on mechanical LF collecting devices were invented by students from the Universiti Putra Malaysia (UPM), Selangor, Malaysia which employed the sweeping or brushing mechanism and discs as the collecting device (Rimfiel and Abadanjumi, 2007). They further concluded that the development of a chain and rake type oil palm LF collector was found satisfactory in picking LF on uneven ground and grass area.

Later, realising the need to come up with different approaches, other researchers have initiated student's projects related to the mechanical type collectors such as studies by Muhammad Azam (2011) and Muhamad Khairul (2013) by using tiny spike or nail type collector (Figure 3). Even though these devices can collect LF, however they are less preferred by the industry as they tend to bruise the fruits. High level of bruised fruits will lead to an increase of free fatty acid (FFA) during storage (Fatin et al., 2014; Hadi et al., 2009).

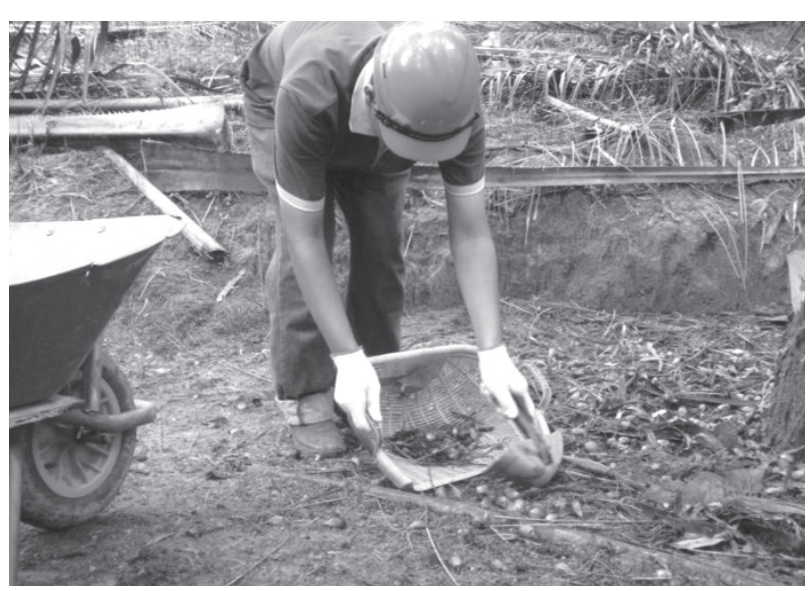

Figure 2. A typical body posture of worker using basket and scoop for collecting loose fruits.

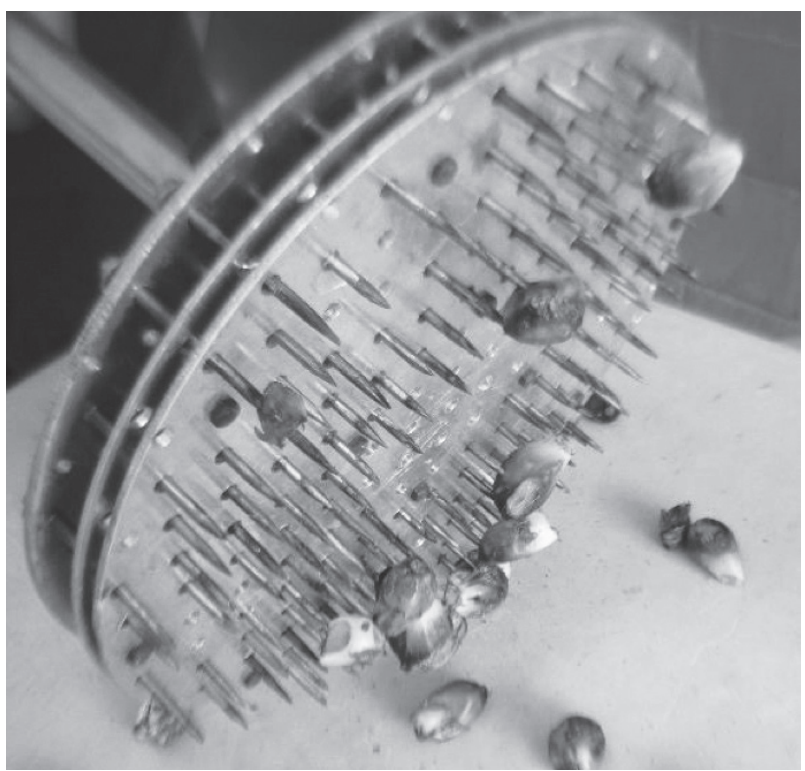

Figure 3. Nail type collector. 
A utility innovation by Zainuddin (2014) revealed that instead of using nails to punch into the LF, the invention used flexible 'fingers' to entrap the LF between the 'fingers'. The entrapped LF were then ejected using a spring mechanism attached to a handle. A similar concept of a mechanical LF collector is the segmented multiple wheels, with each wheel having many synthetic rubber tines that can pick the oil palm fruit during rolling motion as developed by Ahmad Zamri et al. (2016). The device can be manually operated or motorised and with this type of mechanism, it does not bruise the fruits (Figure 4). A comparable concept was developed earlier by Mohd Amir (2009) that utilised the deflecting 'fingers' concept to collect LF in rolling motion. Again, the ability to be operated on uneven terrain and how much productivity gained still need to be further studied in the real oil palm environment.

Another method is an adaptation of the nut collector principle for oil palm LF collection, comprising of a roller-type, cage mechanism to collect LF. The oval-shaped cage is made of several flexible rods that will split open once being pushed towards the LF. Once the LF is entrapped in the cage, the rods will return to their normal position, hence, leaving only clean LF inside. It was claimed that around $30-60 \mathrm{~kg} \mathrm{hr}^{-1}$ of LF can be collected using this device (Mohd Solah et al., 2009). However, based on observations, the roller picker was found not effective for use in soft and wet soils as the LF will tend to further sink into the soil rather than going into the cage.

Some limitations on the mechanical collectors in oil palm plantations are the terrain condition, the vegetation and the various residues at palm circle (Rimfiel and Abadanjumi, 2007). Hence, for effective LF collection, the field must be well prepared to accommodate any machines or equipment.

Although the mechanical type collectors offer a simple and low-cost solution, the total productivity is still uncertain. Furthermore, at one collection point, a longer time is required to collect the scattered LF, with limited amount of LF collected during a single roll. An effective device should be able to overcome all these conditions. If successful, smallholders and small-medium plantations would probably be the main users for this type of collection. Some commonly available mechanical type LF collectors are summarised in Table 1.

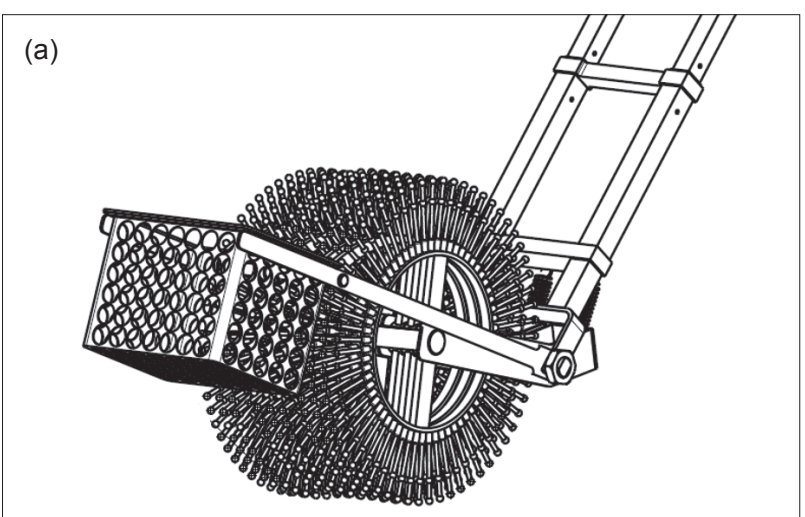

(b)

Figure 4. Roller type with flexible 'finger' collector: (a) manual and (b) motorised.

TABLE 1. SUMMARY OF AVAILABLE MECHANICAL TYPE LOOSE FRUITS (LF) COLLECTING CONCEPTS

\begin{tabular}{lcccc}
\hline Source & Collecting concept/technique & Operation methods & $\begin{array}{c}\text { Productivity } \\
{\text { (kg } \text { min }^{-1} \text { ) }}^{\text {indicator }}\end{array}$ \\
\hline Rimfiel and Abadanjumi (2007) & Chain and rake & Forward/backward push & n.a. & Medium \\
Mohd Solah et al. (2009) & Rotating cage & Roll & $1-6$ & Low \\
Zainuddin (2014) & Nail & Downward push & 2 & Low \\
Muhammad Azam (2011) & Nail & Downward push & n.a. & Low \\
Muhamad Khairul (2013) & Nail & Downward push & n.a. & Low \\
Mohd Amir (2009) & Segmented wheels with tines & Forward/backward push & n.a. & Medium \\
Ahmad Zamri et al. (2016) & Segmented wheels with tines & Forward/backward push & n.a. & Medium \\
Mohd Izmer (2018) & Rotating brushes and screw type & Tractor mounted & 5-6 & High \\
& conveyor & & & \\
\hline
\end{tabular}

Note: *Low <RM 10 000; RM $10000<$ Medium <RM 50 000; High >RM 50000 (including prime mover). n.a - not available. 
One of the promising machines that is currently available in the market is the tractor-mounted LF collecting machine known as Scavenger 3 which employs a rotating brush at the rear of a mini tractor to sweep the LF into its container (Mohd Izmer, 2018). It also has a cleaning mechanism where the collected LF will be conveyed into a series of parallel rods that will filter the debris. With a properly working system, it was claimed that the machine is able to collect LF up to 5 tonnes per day with debris content of less than $5 \%$.

Suction type. A typical LF collecting machine uses an air blower to create a partial vacuum to 'suck up' LF from the ground. Similar to a vacuum cleaner, the machine utilises the same principle where a vacuum suction is created by making pressure differential between the inside and outside of the machine. The LF entering the hose are being pushed into the machine by the outer atmospheric pressure when the blower reduces the pressure inside the barrel. There are two types of vacuum system which are the venturi (open system) and the closed vacuum system (Figure 5). Both systems were tried by numerous researchers to collect the LF and Table 2 shows the comparison between the two systems.

Among the earliest LF collection machines is the one developed by Ahmad et al. (1995) in a joint collaboration between MPOB and UPM. The machine uses a wheelbarrow frame to place two containers; one for LF, while the other is for trash. Using petrol engine as a power source, LF are sucked up through a flexible nozzle. The LF together with trashes go through a separation box, where the heavier LF go into the LF container while the lighter trash goes into the trash container. This machine, on average is capable of collecting 300-400 $\mathrm{kg}$ per day of clean LF, with less than $10 \%$ trash. However, the need to be pushed from palm to palm and limited storage capacity are the weaknesses of this machine.

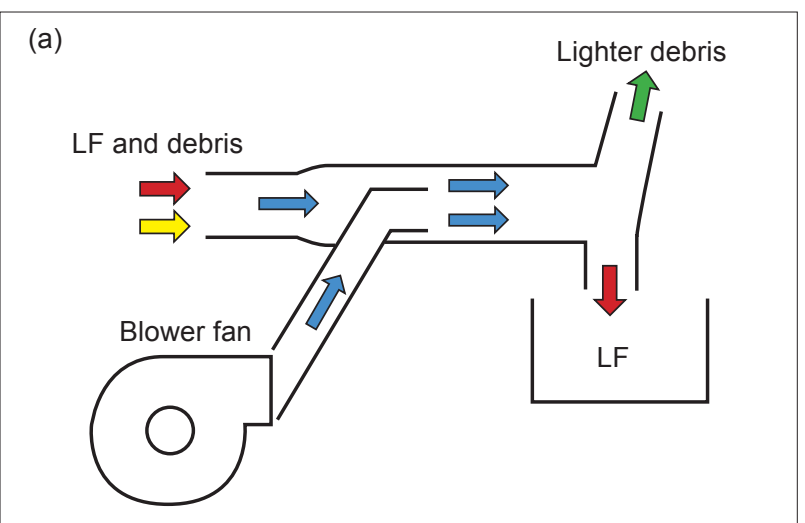

Note: LF - loose fruits.
TABLE 2. VENTURI TYPE $v s$. CLOSED VACUUM

\begin{tabular}{|c|c|c|}
\hline Suction system & Advantages & Disadvantages \\
\hline \multirow[t]{2}{*}{ Venturi } & $\begin{array}{l}\text { - Loose fruits (LF) } \\
\text { can be directly } \\
\text { transferred } \\
\text { into a bin or } \\
\text { container. }\end{array}$ & $\begin{array}{l}\text { - The kinetic energy } \\
\text { per volume of } \\
\text { air is low, hence, } \\
\text { less efficient. }\end{array}$ \\
\hline & $\begin{array}{l}\text { - No injuries to } \\
\text { the LF as no } \\
\text { direct contact } \\
\text { with the fan. }\end{array}$ & $\begin{array}{l}\text { - Higher blower rate } \\
\text { is needed thus } \\
\text { increasing power } \\
\text { consumption. }\end{array}$ \\
\hline Closed vacuum & $\begin{array}{l}\text { Higher suction } \\
\text { can be } \\
\text { generated. }\end{array}$ & $\begin{array}{l}\text { - Maintenance issue } \\
-e . g . \text { need access } \\
\text { to the suction } \\
\text { tank. } \\
\text { - Mud could easily } \\
\text { coat in the } \\
\text { suction tank and } \\
\text { hoses. }\end{array}$ \\
\hline
\end{tabular}

Improvements were made later by Ahmad Zamri and Ahmad (1999) where the suction mechanism was mounted to a three-wheeled vehicle. It was able to collect and carry LF from palm to palm, suitable for uneven and terraced ground, easy to operate and can be handled by just one person. The use of this machine minimised damage to the LF, but the percentage of damage was not stated. This ride-on type machine was capable of collecting LF between 40-60 kg hr ${ }^{-1}$ with a single operator. The only drawbacks were the dirt's clogging issues especially during wet condition and limited storage capacity.

Patent owned by Anthuan (1996) claimed that his invention uses the suction power of a vacuum mechanism to pick up loose fruitlets with ease. It is powered by the power take-off (PTO) from the tractor that also tows the entire assembly. It is also equipped with a rotating separator drum to separate the debris from the LF.

Several attempts have also been conducted by students at UPM where they have developed and tested different suction methods to collect LF (Rimfiel and Abadanjumi, 2007).

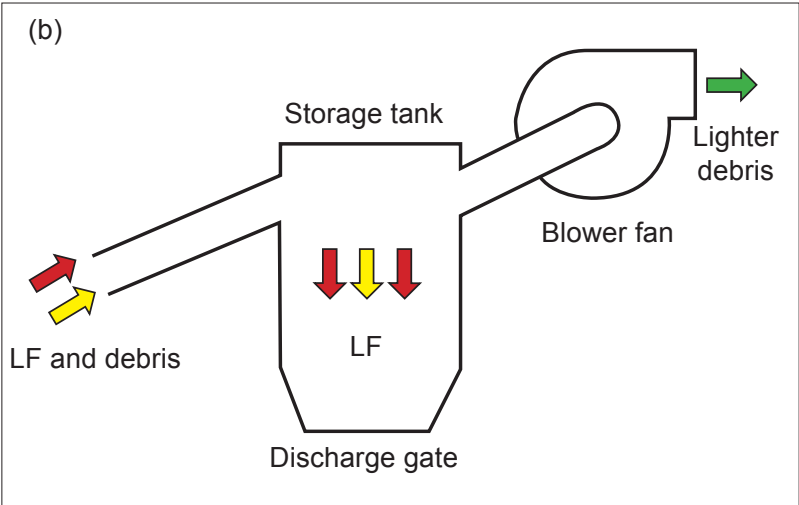

Figure 5. A typical concept of venturi suction (a) and closed vacuum system (b). 
An upgrade version of LF collecting machine that utilises vacuum cyclone concept was developed by Abd Rahim et al. (2012). Using the advantages of cyclone in the barrel, the machine is able to separate debris, hence producing clean LF at the bottom of the barrel. With the capability to collect LF around 4.2-5.1 $\mathrm{kg} \mathrm{min}^{-1}$, this machine is capable of collecting 1200-1500 kg of clean LF in a day with less than 15\% debris. Abd Rahim et al. (2018) later made an improvement by integrating the elevated discharge mechanism to enable the collected LF to be discharged directly into a bin or lorry.

An integrated LF collecting machine was developed by Mohd Zulfahmi et al. (2020) with a combination of vacuum, double layer rotating drums and a tipping bucket. Mounted to a threewheel transporter, it was found that the output was around $600-1000 \mathrm{~kg}$ clean LF in a day with a total operation cost of between RM 73.90-RM 113 per day. Additionally, it was claimed that the debris content was around $5 \%-10 \%$ by weight and with the tipping ability, the clean LF was able to be transferred into a $3 \mathrm{t}$ bin once the bucket was full.

Based on the above inputs and Table 3, it is clear that the suction method is the best option for the plantation industry, because of its greater output. A study by Mohd Ramdhan et al. (2019) found that the minimum air velocity that is required to lift up a single loose fruit is approximately $22.4 \mathrm{~m} \mathrm{~s}^{-1}$ or airflow of $0.21 \mathrm{~m}^{3} \mathrm{~s}^{-1}$. However, to collect groups of LF effectively, airflow of between $0.28-0.33 \mathrm{~m}^{3}$ $\mathrm{s}^{-1}$ (air velocity of $30-35 \mathrm{~m} \mathrm{~s}^{-1}$ ) is required. Hence, more works need to be done to further improve the technology so that it can be commercially used by the industry.

\section{Cost Considerations}

Before introducing a machine to the market, the inventors or machine manufacturers need to understand the situation and expectations from the industry. One of the important factors that need to be emphasised is the working system. It is agreed that collecting individual LF scattered around the palm base is inadequate to improve collection productivity. Therefore, there is a need to improve the system by using a separate gang consisting of three persons (one driver, one collector and one helper to heap the LF). The LF scattered on the ground are first gathered into piles by one dedicated person before the machine performs its task. In this way, however, more workers are needed, making it less appealing to estate management. Therefore, the productivity of the total system must be greater than the manual method to make it economically viable.

Apart from the selling price, the output of the machine is also crucial to be cost-effective. Hence, an estimation of cost per tonne with varying machine costs and productivity was developed as shown in Table 4.

Manual labour cost with assumptions of:

Average productivity: 20 bags per day (20 kg per bag)

Labour cost : RM 2.50 per bag

Labour cost : RM 50 per man per day or RM 150 per day for three workers

To calculate the operational cost of machine, straight line depreciation is used with assumptions of:

Machine's economic life: 5 years

25 working days per month

Labour cost : RM 50 per man per day or RM 150 per day for three workers

Fuel cost : RM 15 per litre per day @RM 2.20 per litre

: RM 33 per day

Repair and maintenance cost: RM 30 per day

Hence, to introduce LF collecting machine in the oil palm plantation, the machine must be able to produce at least $600 \mathrm{~kg}$ LF per man per day or $1.8 \mathrm{t}$ per day for three workers to be economical (below RM 150 per day). This means that productivity must be at least three folds than the manual method.

TABLE 3. SUMMARY OF AVAILABLE VACUUM TYPE LOOSE FRUITS (LF) COLLECTING CONCEPTS

\begin{tabular}{|c|c|c|c|c|}
\hline Source & Collecting concept/technique & Prime mover & $\begin{array}{l}\text { Productivity } \\
\left(\mathrm{kg} \mathrm{min}^{-1}\right)\end{array}$ & Cost indicator* \\
\hline Ahmad et al. (1995) & Direct suction & Wheelbarrow & $1-1.2$ & Medium \\
\hline Anthuan (1996) & $\begin{array}{l}\text { Direct suction with rotating } \\
\text { separator }\end{array}$ & Tractor & n.a & High \\
\hline Ahmad Zamri and Ahmad (1999) & Direct suction & 3-wheeler & 1.13 & Medium \\
\hline Abd Rahim et al. (2012) & Direct suction with cyclone & Tractor or 3-wheeler & $4.2-5.1$ & High \\
\hline Mohd Zulfahmi et al. (2020) & $\begin{array}{l}\text { Direct suction with rotating } \\
\text { separator }\end{array}$ & 3-wheeler & $1.3-2.1$ & Medium \\
\hline
\end{tabular}

Note: *Low <RM 10 000; RM 10 000<Medium<RM 50 000; High >RM 50000 (including prime mover). 
TABLE 4. ESTIMATED TOTAL OPERATION COST $\left(\mathrm{R}^{-1 *}\right)$ AT VARYING MACHINE COST PER UNIT AND PRODUCTIVITY

\begin{tabular}{ccccc}
\hline \multirow{2}{*}{$\begin{array}{c}\text { Machine cost } \\
\text { (RM) }\end{array}$} & \multicolumn{3}{c}{ Estimated productivity (kg per man per day) } \\
\cline { 2 - 4 } & $\mathbf{2 0 0}$ & $\mathbf{4 0 0}$ & $\mathbf{6 0 0}$ & $\mathbf{8 0 0}$ \\
\hline 20000 & 377.22 & 188.61 & 125.74 & 94.31 \\
30000 & 388.33 & 194.17 & 129.44 & 97.08 \\
40000 & 399.44 & 199.72 & 133.15 & 99.86 \\
50000 & 410.56 & 205.28 & 136.85 & 102.64 \\
60000 & 421.67 & 210.83 & 140.56 & 105.42 \\
70000 & 432.78 & 216.39 & 144.26 & 108.19 \\
\hline
\end{tabular}

Note: * Using three workers.

\section{FUTURE DESIGN CONSIDERATIONS}

The design criteria of suction type LF collectors, the machine must have, among others:

a) The ability to collect at least $600 \mathrm{~kg}$ per man per day as a new benchmark.

b) Maximum of three persons to run the system but preferably a single operator. The operator does not need to move from his seat to collect the LF.

c) Having adequate temporary storage capacity (at least able to cover four rows of palm before the compartment is fully loaded with LF).

d) Operated with a minimum cost of materials and maintenance and has a high commercial value.

e) Suited to various types of ground conditions.

f) Ergonomically designed and easy to move along the collection areas in the field.

g) Does not physically injure or damage the collected LF.

h) Having the capability of isolating trash and foreign materials is an advantage to the system.

i) User-friendly, where the operator does not need special skills to operate the machine.

A study indicates that by using the harvesting machine, the amount of detached LF produced during harvesting was reduced by $45 \%$ compared to manual harvesting as the bunch does not hit the ground (Mohd Ramdhan and Rahim, 2014). Perhaps, alternatively, inventors and users should now consider eliminating the task of LF collection by preventing the bunch from falling and hit the ground. Such work has already begun with the development of bunch catcher machine by Azali et al. (2015) where the harvested FFB and LF will drop into the catchment head and then later dropped down into a bucket. Harvesting machine that incorporates the catching mechanism such as grapple to hold the bunch after cutting should be the way forward. This concept of cut and catch has been developed by Abd Rahim et al. (2005; 2010) to minimise the amount of LF during the harvesting process.

Works on exploring the potential of robotic technology to be integrated with LF collecting machine have also been initiated. The possibility of having day and night operation with fewer workers is an interesting opportunity. The presence of open source with affordable cost microcontroller in today's markets has paved the way for an innovative and cost-effective breakthrough.

Most of agricultural autonomous robotics research has been performed in controlled environments such as for fruits picking (Reid et al., 2001; Van Henten et al., 2003; Scarfe et al., 2009). These robots were designed using either vision, global positioning system (GPS), laser and sensorbased navigation control system (Jayantha et al., 2005) and integrated with the manipulators to perform their functions (Christoph et al., 2014). Hence, to suit the concept of autonomous robotic in oil palm plantation environment, more studies need to be conducted.

Siti Nur Amalina et al. (2018) has explored the concept of having incorporated automation features, which involved the elastic cage auto feeding and on a tracking system to track the motion of the loose fruit collector. Nevertheless, this work is still in the early stage.

A robot was developed by Muzakkir and Afandi (2016), with the combination of an embedded platform (Arduino Mega) with robotic mechanism, which revealed convincing results, in terms of its movement, quantity and the quality of the collections as well as stability. Although these works can be considered as still in the infancy stage, the efforts need to be supported. However, we are of the opinion that the highest priority right now is to design an effective collecting mechanism first. Once achieved and proven to work well, this mechanism can be further integrated with available robotic technologies to further enhance its capability. 
Another area that is worth exploring is the self-propelled harvester for collecting (harvest) shell fruits such as hazelnuts, chestnuts, almonds, walnuts, olives, coffee, etc. Few machines were successfully developed and marketed by foreign companies. As for example, Facma Srl, an Italian company, has produced a vacuum collecting machine with rotating sweepers (Figure 6). These sweepers could collect and gather the fruits before being sucked by vacuum into the rear container. With some modifications, this type of machine can be used to collect LF with proper field preparation (Mohd Ramdhan, 2018).

Additionally, various types of unmanned tracked prime mover are available in the overseas market. These transporters have the intelligent system installed where the machine can be remotely operated (Figure 7). Having navigation and camera system, this labour-saving technology has the potential to be utilised in oil palm plantation for various operations from collecting LF to field maintenance activities.

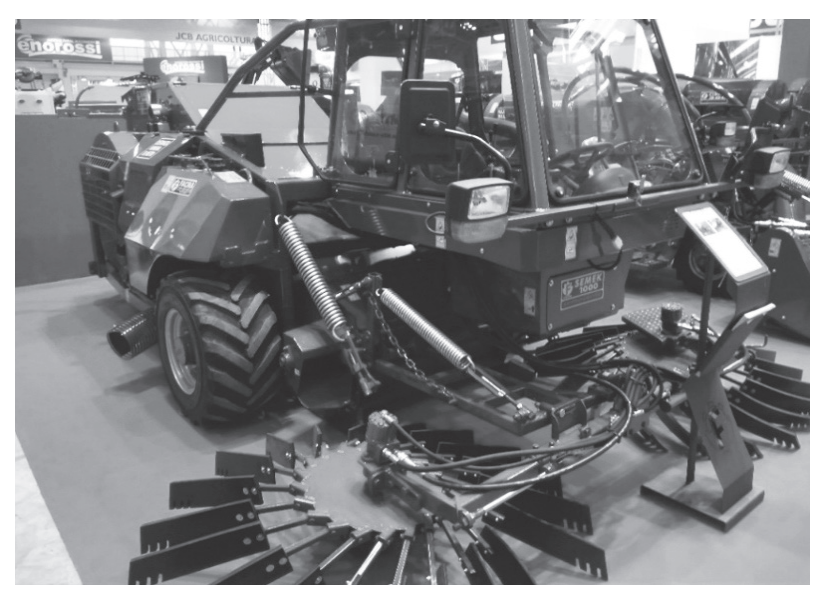

Figure 6. The self-propelled harvester for collecting (harvest) shell fruits.

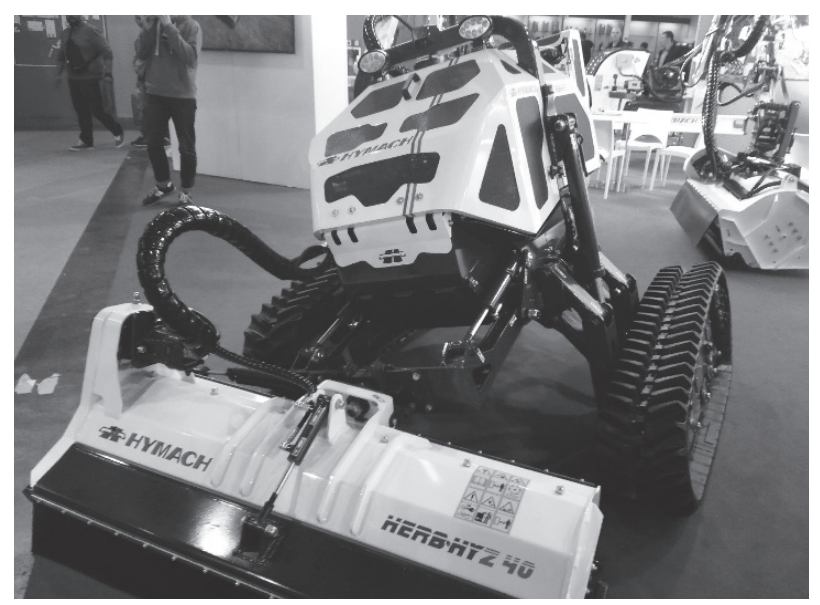

Figure 7. The remote-controlled tool carrier is ideal for slope areas that present the risk of overturning the vehicle with a man on board, or in areas impenetrable by other means.

\section{CONCLUSION}

Conventionally, the technique for collecting LF is by the manual method or hand picking whereby the collected LF are transferred into a bucket or bag. This technique is not only labour demanding and timeconsuming but is also tedious. A cost-effective loose fruit collection system remains the main requirement of oil palm estates. Currently, there are several types of LF collectors such as roller picker, mechanical LF collector and disc plate collector. However, several design concepts that can be improved in terms of the surface condition during operation, minimum damage towards the fruits, quantity of the LF and cost for the tool. In practice, the method of collections should be suitable to operate in various field conditions. In addition, the operator should be comfortable when operating the implement without incurring back pain. Therefore, the criteria of the new design of the collector should work well in various types of field condition, ergonomic for the operator, leading to higher productivity.

Apart from machine performance, other factors such as working system, payment scheme, machinery incentive and workers and management acceptance are among the key components that need to be carefully structured for successful implementation of the mechanised operation.

\section{ACKNOWLEDGEMENT}

The authors wish to thank the Director-General of $\mathrm{MPOB}$ for permission to publish this article.

\section{REFERENCES}

Abd Rahim, S; Abdul Razak, J; Salmah, J; Mohd Solah, D; Mohd Ramdhan, K; Ahmad, H; Yusof, B and Mohd Basri, W (2005). Development of a machine for harvesting tall palms. MPOB Information Series No. 224. palmolis.mpob.gov.my/publication/ TOT/TT-217.pdf

Abd Rahim, S; Mohd Ramdhan, K; Mohd Azwan, M B; Mohd Solah, D and Norman, K (2018). Development of oil palm loose fruit collecting machine with elevated discharge mechanism (Mark iii). Int. J. Engineering Research and Technology (IJERT), Vol. 7 Issue 10: 225-234.

Abd Rahim, S; Mohd Ramdhan, K; Wan Ishak, W I and Norazman, A (2010). Oil palm mechanical harvester - A technical perspective. MPOB Technology No. 32: 1-25.

Abd Rahim, S; Mohd Ramdhan, K and Mohd Solah, D (2011). Chapter 17: Innovation and technologies 
for oil palm mechanization. Further Advances in Oil Palm Research (2000-2010) (Mohd Basri, W; Choo, Y M and Chan, K W eds.). Vol. 1. MPOB, Bangi. p. 569-597.

Abd Rahim, S; Mohd Ramdhan, K; Mohd Solah, D and Aminulrashid, M (2012). Oil palm loose fruits collecting machine (MK III). MPOB Information Series No. 592. palmolis.mpob.gov.my/ publication/TOT/ TT-505.pdf

Abdul Razak, J; Ahmad, H; Johari, J; Malik, N; Yosri, $\mathrm{G}$ and Omar, A (2008). Cantas $^{\mathrm{TM}}$ - A tool for the efficient harvesting of oil palm fresh fruit bunches. J. Oil Palm Res. Vol. 20: 548-558.

Afroza, K L; Fatimah, $\mathrm{M}$ and Rohaya, $\mathrm{M} \mathrm{H}$ (2015). Determination of the harvesting factors of independent smallholder oil palm estate. J. Advanced and Applied Sciences (JAAS) 3(4): 136-144.

Ahmad, H; Ahmad Zamri, Y and Mohd Salih, J (1995). Loose fruit collector. PORIM Information Series No. 19. palmoilis.mpob.gov.my/publications / TOT / TT-19.pdf

Ahmad Zamri, Y and Ahmad, H (1999). Mechanical loose fruit collector (MKII). PORIM Information Series No. 57. palmoilis.mpob.gov.my/publications/TOT/ TT-57.pdf

Ahmad Zamri, Y and Mohd Zulfahmi, Y (2017). Loose oil palm fruit segregating machine and method of segregating loose oil palm fruits using the same. World Intellectual Property Organisation (WIPO) WO 2017010862 A1.

Ahmad Zamri, Y; Mohd Zulfahmi, Y; Ahmad, J and Shawaluddin T (2016). A motorised device for picking and collecting loose fruits. World Intellectual Property Organisations (WIPO) WO 2016072829A1 and PCT /MY2015/000058.

Anthuan, R (1996). Oil palm loose fruitlets picking machine. Malaysian patent No. MY-96004243.

Azali, A; Syed Salim, S A; Abdul Halim, Z A and Azahah, A (2015). Conceptual of mobile oil palm fresh fruit bunch catcher. Int. J. Agriculture Innovations, Vol. 4 Issue 6: 1159-1163.

Azman, I; Siti Mashani, A; Norhidayu, A; Abd Razak, J and Abd Rahim, S (2017). An economic study on mechanisation in oil palm plantations in Malaysia. Palm Oil Economic Review and Outlook Seminar 2017. Pullman Kuala Lumpur City Centre, 17 January 2017.

Christoph Schütz; Julian Pfaff; Jörg Baur; Thomas Buschmann and Heinz Ulbrich (2014). A modular robot system for agricultural applications. Proc. of the International Conference of Agricultural Engineering, Zurich. 6-10 July 2014. p. 1-8.

Darius, E P and Muhammad Fairulnizam, H (2014). Effects of collecting systems and plantation environment on debris accumulation in a collected oil palm loose fruits. Proc. of lnt. Conf. Plt. Phy. 2014. p. $147-151$.

Ezrin Hani Sukadarin; Baba Md Deros; Nur Syazwani Mohd Nawi; Jaharah A Ghani; Ahmad Rasdan Ismail and Junaidah Zakaria (2016). Back pain and the observed factors among oil palm workers. Int. J. Engineering Technology and Sciences Vol. 5 Issue 1: 70-78. DOI: http://dx.doi.org/10.15282/ ijets.5.2016.1.9.1048

Fatin, S A; Rosnah, S and Yunus, R (2014). Effect of chopping oil palm fruit spikelets on the free fatty acid content release rate and its mechanical properties. Int. J. Research in Engineering and Technology Vol. 3 Issue 1: 511-516.

Gan, L T; Ho, C Y; Chiew, J S and Lam, K S (1993). Optimum harvesting standards to maximize labour productivity and oil recovery. 1993 PORIM International Palm Oil Congress - Update and Vision (Agriculture). PORIM, Bangi. p. 195-211.

Gemka Sdn Bhd (2017). Loose fruit cleaner. https:/ / www.gemka.com.my/loose-fruit-cleaner, accessed on 24 March 2017.

Hadi, S; Ahmad, D and Akande, F K (2009). Determination of the bruise indexes of oil palm fruits. J. Food Engineering, 95: 322-326.

Henson, I E (2012). Ripening, harvesting and transport of oil palm bunches. Palm Oil. p. 137-162. DOI: 10.1016/b978-0-9818936-9-3.50008-3.

Jayantha, K; Ray, E; Anthony, C and Craig, M (2005). Automation of an agricultural tractor for fruit picking. Proc. of the 2005 IEEE International Conference on Robotics and Automation. Spain. April 2005. p. 3201-3206.

Kushairi, A; Ong-Abdullah, M; Nambiappan, B; Hishamuddin, A; Bidin, M N I Z; Ghazali, R; Subramaniam, V; Sundram, S and Parveez, G K A (2019). Oil palm economic performance in Malaysia and R\&D progress in 2018. J. Oil Palm Res. Vol. 31(2): 165-194. DOI: https:// doi.org/10.21894/ jopr.2020.0026.

Martin, K; Robert, E and Dublin, S (2016). Harvesting and crop recovery: SALCRA's experience. $12^{\text {th }}$ ISP National Seminar 2016. Kuching, Sarawak. p. 135-147. 
Maizatul-Suriza Mohamed and Abu Seman Idris (2012). Occurrence of common weeds in immature plantings of oil palm plantations in Malaysia. The Planters Vol. 88 No. 1037: 537-547.

Mohd Amir (2009). An apparatus for picking loose fruits such as oil palm or the likes lying on the ground. Malaysian patent No. MY13777l-A.

Mohd Hafiz, M H and Abdul Rashid, M S (2011). Oil palm physical and optical characteristics from two different planting materials. Research J. Applied Sciences, Engineering and Technology, 3(9): 953-962.

Mohd Izmer, A (2018). Tractor mounted loose fruit collecting implement (Scavenger 3). Paper presented at the Labour and Mechanisation Seminar (LAMP 2018). Hotel Mudzaffar, Melaka. 17 October 2018.

Mohd Ramdhan, K (2018). Report on Visit to the International Agricultural and Gardening Machinery Exhibition (EIMA 2018). 7-11 November 2018. Bologna, Italy. MPOB Report OP 455. p. 3-32.

Mohd Ramdhan, K and Abd Rahim, S (2017). Performance of oil palm loose fruits separating machine. J. Oil Palm Res. Vol. 29(3): 358-365.

Mohd Ramdhan, K and Abd Rahim, S (2014). Field evaluation of oil palm mechanical harvesting machines for tall oil palms. J. Oil Palm Res. Vol. 26(2): 125-132.

Mohd Ramdhan, K; Abd Rahim, S and Norman, K (2019). Determination of minimum suction level for collecting oil palm loose fruits. Proc. of the National Convention of Agricultural and Food Engineering 2019. Wisma Tani, Putrajaya. 21 March 2019. p. 198-201.

Mohd Solah, D; Abd Rahim, S and Mohd Saleeh, J (2009). Roller-type oil palm loose fruit picker. MPOB Information Series No. 419. palmoilis.mpob.gov.my/ publications / TOT / TT-419.pdf

Mohd Zohadie, B (1992). Harvesting and transportation of oil palm fresh fruit bunches. Proc. of the National IRPA Seminar (Agriculture Sector). Vol. 1. p. 839-840.

Mohd Zulfahmi Mohd Yusoff; Zamri, A; Abd Kadir, M Z A; Wan Hassan, W Z and Azis, N (2020). Development of integrated loose fruit collector machine for oil palm plantations. Bulletin of Electrical Engineering and Informatics Vol. 9 No. 2: 500-506.

Muhamad Khairul, S (2013). Design and Fabrication of Handy Disc Loose Coconut Palm Collector. Final year student project report. Universiti Malaysia Pahang.

Muhammad Azam, I (2011). Design and Development of Coconut Palm Collector. Final Year Student Project Report. Universiti Malaysia Pahang.

Muhammad Salih, J and Razak, J (1988). Kajian awal terhadap alat memungut buah kelapa sawit terlerai. Seminar Penyelidikan Kejuruteraan Pertanian. 16-17 November. Serdang: Fakulti Kejuruteraan, UPM.

Muzakkir, M N and Afandi, A (2016). Roller picker robot (ropicot 1.0) for loose fruit collection system. J. Engineering and Applied Sciences Vol. 11 No. 14: 8983-8986.

Ng, Y G; Shamsul Bahri, M T; Irwan Syah, M Y; Mori, I and Hashim, Z (2013). Ergonomics observation: Harvesting tasks at oil palm plantation. J. Occup. Health, 55(5): 405-414.

Nizaroyani Saibani; Ariff Azly Muhamed; Mohd Faizal Maliami and Rasyidah Ahmad (2015). Time and motion studies of manual harvesting methods for oil palm fruit bunches: A Malaysian case study. Jurnal Teknologi (Sciences and Engineering), 74(3): 77-83.

Nur Syazwani Mohd Nawi; Baba Md Deros; Mohd Nizam Ab Rahman; Ezrin Hani Sukadarin and Norani Nordin (2016). Malaysian oil palm workers are in pain: Hazards identification and ergonomics related problems. Malaysian J. Public Health Medicine 2016, Vol. (Suppl. 1): 50-57.

Nur Syazwani Mohd Nawi; Baba Md Deros; Mohd Nizam Ab Rahman; Norani Nordin and Ezrin Hani Sukadarin (2015). Mechanized tools and technovation machinery in palm oil plantations: Utilization or rejection? Paper presented at the International Symposium on Advancement in Ergonomics and Safety 2015. Universiti Malaysia Perlis, Perlis. 30 November 2015.

Nurul Fadilah, M N; Er, A C; Rewati, K; Yaakob, H I and Amran, A (2019). Good agricultural practices amongst oil palm smallholders: A case study in Sabah. Revista de Ciencias Sociales y Humanidades Vol. 4 No. 17: 347-355.

Owolarafe, K; Olabige, M T and Faborode, M O (2006). Physical and mechanical properties of two varieties of fresh oil palm fruit. J. Food Engineering, 78(2007): 1228-1232.

Razali, H; Halim, A S M A and Roslan, S (2012). A review of crop plant production and ripeness forecasting. Int. J. Agriculture and Crop Sciences Vol. 4 No. 2: 54-63. 
Renel, M A; Pepito, M B; Delfin, S S and Engelbert, K P (2013). Determination of some physical and mechanical properties of oil palm fruit. USM RED J. Vol. 21 No. 2: 61-70.

Rimfiel, J and Abadanjumi, E (2007). Performance evaluation of a terrain accommodating oil palm loose fruit collector. Pertanika J. Science and Technology Vol. 15 No. 1: 15-23.

Reid, J N; Miles, S J; Butler, J; Baldwin, $\mathrm{M}$ and Noble, R (2001). Automatic mushroom harvesting development. J. Agricultural Engineering Research, 78: 15-23.

Scarfe, A J; Flemmer, R C; Bakker, H H and Flemmer, C L (2009). Development of an autonomous kiwifruit picking robot. Proc. of the $4^{\text {th }}$ International Conference on Autonomous Robots and Agents. 10-12 February, New Zealand. p. 380-384.
Seedlink (2008). Loose fruit vs. lost income. Seedlink Vol. 2/6: 8. A bimonthly publication by Sime Darby Plantation Sdn Bhd, March 2008. Subang Jaya.

Siti Nur Amalina, M S; Muhammad Razif, M; Zulhakim, W; Muhamad Aznan, M and Nur Hanani, Z (2018). Integrating automation in an oil palm loose fruits collector. Paper presented at the 2018 MSAE Conference. Serdang, Selangor, Malaysia. 7-8 February 2018. Paper No: MSAE2018-AMA014. p. 279-283.

Van Henten, E J; Van Tuijl, B A J; Hemming, J; Kornet, J G; Bontsema, J and Van Os, E A (2003). Field test of an autonomous cucumber picking robot. Biosystems Engineering, 86(3): 305-313.

Zainuddin, I (2014). Loose fruit picker. Malaysian patent No. MY152054. 